\title{
Nutrition in Sub-Saharan Africa: Setting the Stage for a Post-2015 Take-off
}

\author{
Anna Lartey
}

\begin{abstract}
The MDGs have provided opportunities for addressing undernutrition in sub-Saharan Africa. The link between addressing undernutrition and human capital development has been a key message. The African Union (AU) now realises the unique role nutrition plays in Africa's development. The AU's NEPAD (New Partnership for Africa's Development) and CAADP (Comprehensive Africa Agriculture Development Programme) have incorporated nutrition in their programmes. Additionally, 30 October is now commemorated as Africa Food and Nutrition Day. Through the SUN Movement, many African countries have committed to address undernutrition. Moving forward, the momentum for nutrition must be sustained. Commitments made must be reflected in increased resources and effective programmes. Africa must take advantage of ICT (information and communication technology); strengthen democratic structures and empower women to maximise their contribution to development; create safety nets for the vulnerable; and close the inequity gap. Civil society must remind governments of their commitments. Sub-Saharan Africa must take advantage of this favourable environment and put the continent on an accelerated course of action.
\end{abstract}

\section{Introduction}

In 2000, world leaders came together to agree on a set of development goals that all countries could align themselves with and that they could commit to achieving by 2015. The Millennium Development Goals (MDGs) were lauded and hopes were high that these goals would move the world forward. However for many developing countries, especially in sub-Saharan Africa, to achieve the MDGs in the midst of a heavy debt burden was a challenge. The Heavily Indebted Poor Countries (HIPGs) facility introduced by G8 finance ministers to the world's poorest countries was to bring some relief. The HIPC funds were to achieve two outcomes: reduce the debt burden and redirect funds to development programmes to accelerate the implementation of the MDGs. Not surprisingly, of the 39 countries that qualified for the HIPC facility, about 85 per cent (33) were in sub-Saharan Africa (World Bank 2001) and indeed many of these countries had some debts cancelled. As would become clear, debt relief, though very important, was alone not enough to accelerate progress in achieving the MDGs. Five years into the MDG goal date of 2015, a World
Bank report monitoring the MDGs concluded that 'sub-Saharan Africa is not on track to achieve a single MDG, and it is the only region where child malnutrition is not declining' (World Bank 2005). Sub-Saharan Africa had two huge factors militating against its progress with the MDGs: high debts and a high malnutrition burden. It was made clear that unless nutrition is repositioned as a central part of development, achieving the MDGs will be an uphill task (World Bank 2006). Addressing malnutrition is crucial for achieving at least six out of the eight MDGs. Therefore regions with a high malnutrition burden, such as sub-Saharan Africa are not likely to meet the MDGs.

'Millennium Development Goals' became the buzz phrase in most reports and speeches and yet there was no concerted strategy to pull vulnerable countries out of the situation they found themselves in. The Lancet Nutrition Series in 2008 distilled the nutrition issue in a way that was easy to tackle; they reported that ' 80 per cent of the world's undernourished live in just 20 countries' (Bryce et al. 2008). If nutrition 
action can be focused on these countries, marked improvements will be seen in achievement of the health MDGs. The Lancet Nutrition Series was frank and bold in pointing out that 'the international nutrition system is fragmented and dysfunctional' (Morris et al. 2008). As harsh as these words may have sounded, it achieved a lot in bringing nutrition to the forefront of the global agenda. The global nutrition community started reorganising to tackle the issue of malnutrition, culminating in the birth of the two global groups in September 2010 - Scaling Up Nutrition (SUN) Movement and 1,000 Days. The following section will describe how the MDGs have influenced commitment to addressing nutrition in sub-Saharan Africa.

\section{Have the MDGs had any traction in sub-Saharan Africa?}

To clearly address this question, it is important that we look at the situation of nutrition in the sub-region prior to the MDGs. Previous efforts by the African Union (AU) to include nutrition in its deliberations started with the formation of the African Task Force on Food and Nutrition Development in 1987. The objective was to sensitise African policymakers to the importance of food and nutrition security in socioeconomic development (AU 2005). In preparing for the International Conference on Nutrition in Rome, 1992, the sub-region came up with the African Regional Nutrition Strategy (1993-2003) as Africa's response to the deteriorating nutrition situation on the continent. The Strategy was endorsed by African heads of state at its Assembly in June 1993. In this document, member states were urged to allocate adequate funds to achieve the objectives of the Strategy. Other nutrition resolutions endorsed included the Control of Micronutrient Deficiencies in Africa, in 1996; Global Strategy on Infant and Young Child Feeding; Global Strategy on Food, Physical Exercise and Health; and the World Food Summit 1996 resolution (AU 2005). The extent to which these endorsements were translated into effective programmes and activities within countries is hard to tell as the nutrition situation of the continent showed little improvement.

The advent of the MDGs caused the searchlight to be focused on Africa. The Lancet 2008 league table for stunting showed that of the 36 countries where this is a significant problem, about 60 per cent are located in sub-Saharan Africa (Black et al.
2008). It became clear that for Africa to reduce its alarmingly high maternal and child mortality statistics, it must address the high burden of malnutrition. The link between malnutrition, human capital development and economic growth has become the message. To put nutrition back on the AU's agenda, it began with the revision of the African Regional Nutrition Strategy (2005-2015), this time emphasising the importance of nutrition in poverty alleviation and in the achievement of the MDGs (AU 2005). The document was used to raise awareness among governments and to advocate for resources to address malnutrition. The Comprehensive Africa Agriculture Development Programme (CAADP) was established as a sector programme under the New Partnership for Africa's Development (NEPAD). CAADP was endorsed by African heads of state and governments in October 2005. The aim of CAADP is to eliminate hunger and reduce poverty through agriculture. Pillar 3 of CAADP focuses on improving food security to support African countries to meet MDG 1 by the 2015 deadline. A direct nutrition activity under this programme is the home-grown school feeding initiative that provides one hot meal daily to primary school children. The school feeding programme is expected to contribute to the MDGs on education, by improving school attendance, student achievement and gender equality.

Responding to the concern that nutrition issues are not adequately reflected in the AU's NEPAD and CAADP processes (NEPAD and CAADP 2008), the Pan African Nutrition Initiative (PANI) was established in 2008 to address this gap. Specifically, under PANI, the nutrition lens tool is applied as a way to integrate nutrition into all four pillars of the CAADP process and to review the potential impact of projects on nutrition and how these will contribute to the achievement of the MDGs. Additionally, under NEPAD, a ten-year strategy was drafted, with a three-year action plan (2008-11), for the reduction of vitamin and mineral deficiencies.

The advent of the SUN Movement added a new dimension to the ongoing nutrition regeneration process on the continent. SUN infused new energy into addressing malnutrition. Many African countries quickly signed on as SUN early riser countries. Currently, of the 34 SUN countries, 23 are in sub-Saharan Africa. Leaders from these countries are committed to tackling 
undernutrition. Countries have formed multistakeholder platforms that bring government ministries, donors, civil society and businesses together to address undernutrition. An unprecedented outcome of SUN in some countries is the formation of civil societies to advocate for nutrition. SUN has taken roots in sub-Saharan Africa. The African Union's chief executive, together with three African heads of state and a minister of finance are among the 27 global leaders appointed by the UN Secretary-General in April 2012 to lead the SUN Movement.

At its 15th Summit in Kampala in 2010, the AU endorsed the establishment of an Africa Food and Nutrition Day to be commemorated annually by all states on 30 October. The objective of this day is to continue to bring Africa's food and nutrition issues to the fore and sustain the momentum towards achieving the MDGs.

To further promote and give visibility to nutrition issues in the region, and to encourage African leaders to take responsibility for addressing malnutrition, the former president of Cape Verde (Antonio Manuel Mascarenhas Gomes Monteiro) was appointed Nutrition Advocate for West and Gentral Africa in July 2011. His role, among others, is to advocate with leaders of African countries to place nutrition at the centre of their development efforts.

Realising that adequate capacity would be needed to support the implementation of the country programmes, since 2011 CAADP has embarked on regional nutrition workshops to build the capacity of countries to address undernutrition.

Developing adequate capacity to implement nutrition initiatives and policies is the backbone on which the success of programmes rest. Inadequate capacity in Africa appears to be one of the causes of poor programme outcomes. To bridge the nutrition capacity gap, the West Africa Health Organization (WAHO), working jointly with UNICEF (United Nations Children's Fund) and Hellen Keller International, are spearheading efforts for the establishment of a West Africa Nutrition Capacity Development Initiative (WANCDI). This initiative is the outcome of a nutrition capacity workshop held in Dakar, Senegal in 2009. The participant consensus statement recognised the urgent need for nutrition capacity development. This position was endorsed by West Africa health ministers in 2009. Work on WANCDI has started with efforts to build an inventory of existing nutrition research training programmes in the West Africa region.

There is no doubt that the MDGs have brought unprecedented opportunities for the improvement of nutrition in the sub-region and the MDGs have been used to leverage change for nutrition in many ways. Although sub-Saharan Africa is unlikely to meet the goals, the solid foundation laid for improved nutrition in the past 15 years is essential for the Post-2015 Development Agenda to take off. This foundation was needed to prepare the ground and enable the MDGs to take root. Our leaders have been sensitised, commitments have been made, the environment is now very conducive and the post-2015 MDGs should see sub-Saharan Africa on the rise. The endorsements and commitments must now be translated into concrete programmes and resources for nutrition.

\section{Sub-Saharan Africa taking advantage of the Post-2015 Development Agenda}

Moving forward, as a latecomer, sub-Saharan Africa can take advantage of the latest technologies and learn from regions that have been successful at reducing malnutrition. For sub-Saharan Africa to take advantage of the Post-2015 Development Agenda there is still a lot to be done. First, the momentum for nutrition that has been built in the region over the past 15 years must be sustained. Commitment from leaders must be seen in concrete terms such as budget lines for country nutrition programmes. Currently, in many countries in the region, without donor support, there will be no nutrition programmes.

Second, Africa must learn from the success stories of other regions and countries that have been able to reduce malnutrition in a short time. The success of the Brazilian Zero Hunger Project provides a lot of lessons. Key among them is the high-level commitment shown by a political leader. In less than ten years, Brazil was able to reduce malnutrition, hunger and poverty. President Lula's re-election in 2006 has been attributed to this remarkable feat of addressing food insecurity, poverty and hunger (Kilpatrick 2011). Brazil's case is testimony that paying attention to the people's needs and rights to adequate nutrition can be translated into votes. 
Third, Africa must take advantage of the latest information and communication technology (ICT) to improve maternal and child services. Africa now has more mobile phone subscribers than the USA or EU (Quartz 2012). This is a huge potential that can be tapped to deliver services. For example, in Ghana, mobile phone applications are being used to reach pregnant women to provide health messages in local languages. Pregnant women in rural areas are taught to use mobile phones to call ambulances in emergencies (HealthWorks Collective 2012).

Fourth, there is the need to strengthen democratic structures to enhance national stability and reduce internal conflicts. A lot has been achieved on this front. Democracy is developing roots on the continent and there are model countries for others to follow. Coups d'état that were characteristic of sub-Saharan Africa are gradually fading. What we need to do now is to consolidate our democratic structures to effectively support development. Historical events on the continent show that development comes to a halt in the midst of wars and insecurity.

Fifth, the contribution of women to national development must be recognised. Women must be empowered through the access of girls to education and the access of women to resources that will enable them reach their full potential and contribute to national development. Dr James Kwegyir Aggrey, a renowned educationist in the then Gold Coast (now Ghana), in the 1920s said: 'The surest way to keep a people down is to educate the men and neglect the women. If you educate a man, you educate an individual, but if you educate a woman you educate a nation' (Wikipedia n.d.). The veracity of this statement holds firm today and reflects the extent to which women's empowerment permeates the entire household, community and nation.

Sixth, the post-2015 era cannot be business as usual. It must be the time to take bold but decisive steps. Reducing maternal and child mortality has been the most challenging of the goals for all African countries. This calls for focused policies, innovation and passion to end these senseless deaths. For example, in Malawi, efforts are in place to encourage health facility deliveries. Shelters have been constructed on hospital premises where pregnant women can come in for a few days prior to their delivery to ensure they deliver under the supervision of a health attendant. Another bold step is Ghana becoming the first African country to introduce a combined vaccine (pneumococcal and rotavirus) in 2012, to simultaneously combat the two leading causes of the world's biggest childhood killers: pneumonia and diarrhoea (BBC News Africa 2012). Post-2015, Africa must leap. The great teacher (Mwalimu: President Nyerere) said: 'We [Africa] must run while they walk' (Smith 1972).

Seventh, the food, fuel and financial crisis in 2008 clearly revealed the vulnerability of the poor and food insecure (de Pee et al. 2010). Safety nets must be created for the most vulnerable. Ghana's success in achieving the poverty target of MDG 1 has been attributed to the introduction of the Livelihood Empowerment Against Poverty (LEAP) programme for the poor. This programme provides direct cash transfers to the poorest in the society. However, such programmes must be implemented with caution and with the aim of getting beneficiaries out of poverty through the creation of alternative livelihood sources that are sustainable and don't create dependency. We must be guided by the popular Chinese proverb: 'If you teach a man (or woman) to fish you feed him (her) for a lifetime'. While it is not always possible to anticipate or prevent crisis situations, their effects can be mitigated if structures are put in place to cushion those most likely to be affected.

Eighth, African governments must work to close the inequity gap by ensuring that poor people have access to basic services such as potable water, health care and schools. This requires prioritising, focusing on policies and programmes that will improve the health statistics; of these, investing in nutrition-specific and nutrition-sensitive programmes have been shown to be effective.

The SUN Movement has set the stage for different disciplines to work together within countries to address undernutrition. These platforms must be sustained, as the post-2015 MDGs will continue to require key stakeholders working in concert to make maximum impact.

Ninth, the Post-2015 Development Agenda will require comprehensive data collection systems to regularly monitor indicators and put remedial 
actions in place where needed. There is also the need to monitor political commitment to addressing undernutrition. We have seen the numerous endorsements by African leaders. How can these be translated into action? Who holds governments accountable for their endorsements? How can commitments on the part of governments and donors be assessed? Looking ahead, a new tool has just been released for this purpose: the Hunger and Nutrition Commitment Index (HANCI) (te Lintelo et al. 2013). This tool will enable governments to be assessed for their political commitment to reducing hunger and undernutrition. It is hoped that using such tools can be used to construct a league table indicating the most committed and least committed governments in sub-Saharan Africa. This would then be published periodically and lead to rewards for performing governments in the form of support and global recognition.

Tenth, currently there are ongoing consultations in the developed world on the Post-2015

Development Agenda. Given that these goals most concern developing countries, Africa's representatives should be proactive in shaping the Post-2015 Development Agenda. It is not enough for global players to slap the developing world with development goals to be achieved in a specified timeframe without giving direction on how these can be achieved and support to do that. In the global village we have created, achieving the MDGs is a concern for all - both developed and developing countries - and thus the post-2015 development goals should be an agenda for all.

\section{Conclusions}

There is no doubt that African governments will seize this opportunity to improve nutrition. The focus now is on Africa. If you are down, there is nowhere else to move but up. The process of acceleration has started and there is no turning back. Undernutrition is holding the continent back and our leaders are poised to take action. The people are well aware of their rights. Just as they are demanding probity and accountability, the people will demand good nutrition for all as a right. African countries must organise themselves and push with a common voice and purpose for the support they need to address undernutrition. Addressing undernutrition must be positioned as a regional and national agenda, protected by national constitutions and to be pursued irrespective of which political party is in power. This is critical to ensuring that the momentum is not lost as a result of changes in government. Finally, we owe it to ourselves and future generations to ensure political and economic stability on the continent.

In the meantime, there is a lot the rest of the world can do to support Africa's efforts. The voices and actions that brought addressing nutrition to the global agenda started with strong support from the North. These voices must be loud and sustained. Addressing undernutrition requires commitment and support in various forms. Resources must be made available at all levels to support Africa's efforts. Some countries in Africa, such as Rwanda and Tanzania, are making remarkable progress in reducing undernutrition. Such countries must be given the recognition and encouragement to do more. Africa needs to build her human and institutional capacity to support this momentum at the country level. Action on this front is urgently needed. Civil society from both the North and South must continue to push and keep nutrition issues at the fore. In this respect, leadership and champions for nutrition at all levels are needed from both the North and South.

In conclusion, the MDGs have created opportunities to address the issue of nutrition in the region. Although sub-Saharan Africa's progress in achieving the MDGs has been slow, the commitment and sensitisation that have been achieved at the highest levels nationally and globally within the past 15 years have created the necessary traction for post-2015 development goals to take off. These are exciting times for subSaharan Africa. According to the International Monetary Fund (IMF 2012) ten of the 25 countries with the highest projected annual growth rate from 2013-17 are in sub-Saharan Africa. African leaders must take advantage of this favourable environment and goodwill for Africa and pull the continent out of the heavy burden of malnutrition it carries presently. If we do all the right things, there is no doubt that post2015 will see sub-Saharan Africa on the rise. 


\section{References}

AU (African Union) (2005) 'Sustainable Access to Treatment and Care for the Achievement of the Millennium Development Goals', 2nd Ordinary Session of the Conference of African Ministers of Health, Gaborone Declaration, Gaborone, Botswana, 10-14 October

BBC News Africa (2012) Ghana Pioneers New Child Vaccines, 27 April, www.bbc.co.uk/news/worldafrica-17865404 (accessed 11 May 2013)

Black, R.E.; Allen, L.H.; Bhutta, Z.A.; Caulfield, L.E.; De Onis, M.; Ezzati, M.; Mathers, C. and Rivera J. (for the Maternal and Child Undernutrition Study Group) (2008) 'Maternal and Child Undernutrition: Global and Regional Exposures and Health Consequences', Lancet 371.9608: 243-60

Bryce, J.; Coitinho, D.; Darnton-Hill, I.; Pelletier, D. and Pinstrup-Anderson, P. (for the Maternal and Child Undernutrition Study Group) (2008) 'Maternal and Child Undernutrition: Effective Action at National Level', Lancet 371.9611: 510-26

de Pee, S.; Brinkman, H.J.; Webb, P.; Godfrey, S.; Darnton-Hill, I.; Alderman, H.; Semba, R.D.; Piwoz, E. and Bloem, M.W. (2010) 'How to Ensure Nutrition Security in the Global Economic Crisis to Protect and Enhance Development of Young Children and Our Common Future', Journal of Nutrition 140: 138S-42S

HealthWorks Collective (2012) Mobile Health Around the Globe: Ghana - Changing the Very Essence of Healthcare, 13 August, http://healthworkscollective.com/rhona-finkel/ 42661/mobile-health-ghana-changing-veryessence-healthcare (accessed 4 May 2013)

IMF (2012) World Economic Outlook. Coping with High Debt and Sluggish Growth, Washington DC: International Monetary Fund

Kilpatrick, K. (2011) Fighting Hunger in Brazil: Much Achieved, More to Do, http://oxf.am/4iQ (accessed 13 June 2013)
Morris, S.S.; Cogill, B. and Uauy, R. (for the Maternal and Child Undernutrition Study Group) (2008) 'Effective International Action Against Undernutrition: Why has it Proven so Difficult and What can be Done to Accelerate Progress?', Lancet 371: 608-21

NEPAD and CAADP (New Partnership for Africa's Development and Comprehensive Africa Agriculture Development Programme) (2008) The Pan African Nutrition Initiative, www.wemos.nl/ files/.../PanAfricanNutritionInitiative.pdf (accessed 13 June 2013)

Quartz (2012) Africa Now Has More Mobile Subscribers than the US or EU, 20 December, http://qz.com/38349/africa-now-has-moremobile-subscribers-than-the-us-or-eu/ (accessed 1 May 2013)

Smith, W.E. (1972) We Must Run While They Walk: A Portrait of Africa's Julius Nyerere, 1st edn, London: Random House

te Lintelo, D.; Haddad, L.; Lakshman, R. and Gatellier, K. (2013) The Hunger and Nutrition Commitment Index (HANCI). Measuring the Political Commitment to Reduce Hunger and Undernutrition in Developing Countries, Brighton: IDS

Wikipedia (n.d.) Biography of Dr James Emman Kwegyir Aggrey, https://en.wikipedia.org/wiki/ James_Emman_Kwegyir_Aggrey (accessed 13 June 2013)

World Bank (2006) Repositioning Nutrition as Central to Development. A Strategy for Large-scale Action, Washington DC: World Bank

World Bank (2005) Global Monitoring Report 2005, Washington DC: World Bank

World Bank (2001) Heavily Indebted Poor Countries, http://web.worldbank.org/WBSITE/ EXTERNAL/COUNTRIES/AFRICAEXT/ 0,,contentMDK:20236241 menuPK:488504 pagePK:146736 piPK:226340 theSitePK: 258644,00.html (accessed 13 June 2013) 